\title{
Demand-Side Energy Management in Smart Buildings: A Case Study
}

\author{
Nazli Hasanova ${ }^{1 *} \mathbb{( D}$, Secil Varbak Nese ${ }^{2}$ (D) \\ ${ }^{1 *}$ Marmara University, Institute of Pure and Applied Sciences, M.Sc.Student, Istanbul, Turkey. (e-mail: nana.hesenova1998@ gmail.com). \\ ${ }^{2}$ Marmara University, Electrical Electronics Engineering Department, 34722, Kadikoy, Istanbul, Turkey (e-mail: secil.varbak@marmara.edu.tr).
}

\section{ARTICLE INFO}

Received: Jul., 12. 2021

Revised: Sep., 23. 2021

Accepted: Oct., 24. 2021

Keywords:

Smart buildings

Energy management system

Demand side management

Fuzzy logic controller

\section{Corresponding author: Nazlı Hasanova}

ISSN: $2536-5010$ e-ISSN: 2536-5134

DOI: https://doi.org/10.36222/ejt.969881

\section{ABSTRACT}

Electrical energy is indispensable in our daily life with the developing technology. The most important feature is reliable and sustainable transmission of electrical energy to consumers is to provide the supply-demand balance in real-time. The ever-increasing demand for electrical energy, gradual depletion of traditional resources used to meet demand, and increasing dependence on foreign sources resulted in diverse electricity generation plants. As a result of this diversity, with the increase in the importance of electricity storage systems and awareness of energy-saving, Demand Side Management (DSM) gains great importance in ensuring supply-demand balance. DSM reduces costs by scheduling consumption instead of increasing generation to balance supply and demand. Residences constitute a large part of energy consumption worldwide, so DSM applications in buildings increase efficient usage of energy. Various management strategies can be used to save energy depending on the building type. In this article, an overview of Energy Management System (EMS) strategies to increase energy efficiency is presented. Then a case study is carried out in a residential model in Matlab/Simulink environment. The electrical devices were controlled with a Fuzzy Logic Controller (FLC), taking into account comfort, cost, and Demand Response (DR). In addition, Renewable Energy Resources (RES) to demonstrate their contribution were modelled and integrated into the system. Finally, case studies were conducted, and a comparative analysis of obtained results was carried out.

\section{INTRODUCTION}

With the increase in the world population, electrical energy consumption continues to increase continuously [1]. One of the main problems that may be encountered in the near future is increasing power demand. By 2028, electricity demand will increase by $19 \%$, while existing infrastructure efficiencies could only increase by $6 \%$, is estimated [2]. Effective and efficient energy usage becomes essential due to technological developments, population growth, and increasing concern about the depletion of fossil fuels [3]. With the growing urbanization in recent years, the rising number of buildings causes an increase in energy consumption [4]. In worldwide, energy used in buildings can be $45 \%-50 \%$ of total energy consumption in countries [5]. Especially in energy crises and environmental pollution, energy-saving and efficiency in buildings are essential [6]. These reasons encourage building and business owners to use new technologies to reduce energy consumption and environmental pollution [2]. The reason for emergence and interest in term Smart Building (SB) is that it includes systems that provide energy efficiency and consumer comfort [7].
The most important unit of SB systems is Building Energy Management System (BEMS), which is applied to manage energy effectively [8,9]. This technology manages and controls energy flow in building through different types of information to ensure operational safety, reliability, and economy by automating DR approaches [4]. Research on comfort and energy management in buildings has gained considerable momentum in the last decade [10].

This study aims to examine the energy management strategies and techniques in buildings in the literature, model and control basic electrical appliances, and address the management of energy consumption in buildings. An FLC has been implemented to control the usage of loads with a demand-side strategy that considers both total building energy consumption and comfort conditions. With DSM, both cost and energy consumption were saved by shifting load demand during hours when consumption is intense, and unit price of electricity is high compared to the tariff, to lower and off-peak hours or the hours of RES generation.

In this study, firstly, SB concept was examined, and studies on BEMS to increase energy efficiency in buildings 
were investigated in detail. Then, a residential model was created in Matlab/Simulink software, and case studies were carried out. Next, FLC has been designed to control electrical devices, taking into account comfort, cost, and DR. In addition, RES has been modeled and integrated into the model in case studies. Finally, a comparative analysis was carried out with all obtained results.

\section{SMART BUILDING}

Since the past, under the developments in all fields lies the effort of people to improve themselves and to bring their own lives to a more comfortable and comfortable level [11]. Especially after the 2nd World War, significant progress has been made in the building sector [12]. With machine power usage and Industrial Revolution, new styles and materials have emerged in construction and architecture. For the first time, these developments came together in "High-Tech" buildings in the 1970s. Also, many positive results, adverse effects such as a large amount of energy loss emerged. The first energy crisis in 1973 led people to re-examine used energy methods and created awareness about energy saving [13]. SBs, whose most important feature is to achieve high comfort with less energy, ensure sustainability by minimizing energy consumption, and prevent environmental pollution [7], first emerged in the USA in the early 1981's [13]. SBs can be defined as buildings that maximize energy efficiency without concession comfort of users, have communication systems, and contain an automatic control system developed for monitoring systems such as ventilation, heating, lighting, and security [14]. SB structure includes energy generation, storage, demand management, control, and communications controlled by BEMS [10].

Since the second half of the 21 st century, developments in automation and computer fields have caused SBs to become widespread [15]. As a result, next-generation SBs must not only consider features such as weather conditions and predicted occupancy. Still, they must also be adaptable enough to maximize RES and energy storage usage, times that the unit price of electrical energy is low.

\section{ENERGY MANAGEMENT STRATEGIES FOR BEMS}

BEMSs are computer-based central systems that control and record all separate systems in a building, such as electrical systems, mechanical systems, elevators, air conditioning, lighting, security, monitoring, access, and emergency alarms $[16,17]$. According to different advanced functions or control logic, these systems can monitor and control energy usage in industry and buildings [10]. There are two types of BEMS methods, active and passive. Passive methods are based on presenting future strategies and improving energy awareness of users to affect and reduce energy usage in buildings indirectly. Active methods are based on mix of actuators and sensors infrastructures in the building. They also aim to reduce energy waste through the control of SB actuators and devices [10]. This study examines active approaches under DSM, DR, Time of Use (TOU) tariffs according to BEMS management strategy, scheduling according to RES/battery systems, and optimization for generation uncertainties in RES.

\subsection{Demand Side Management}

DSM is a portfolio of measures to improve the energy system on the consumption side [18]. DSM, a function of EMS, refers to programs implemented by electrical utilities to control energy consumption in response to the changing operating conditions of the grid. The objectives of implementing a DMS plan range from reducing end-user operation costs to reducing transmission/distribution losses and carbon emissions [19]. DSM aims to educate electricity consumers to change their electricity usage patterns to reduce demand to provide continuous energy supply. DSM uses different strategies, as shown in Figure 1, especially peak demand reduction and load shifting [20].

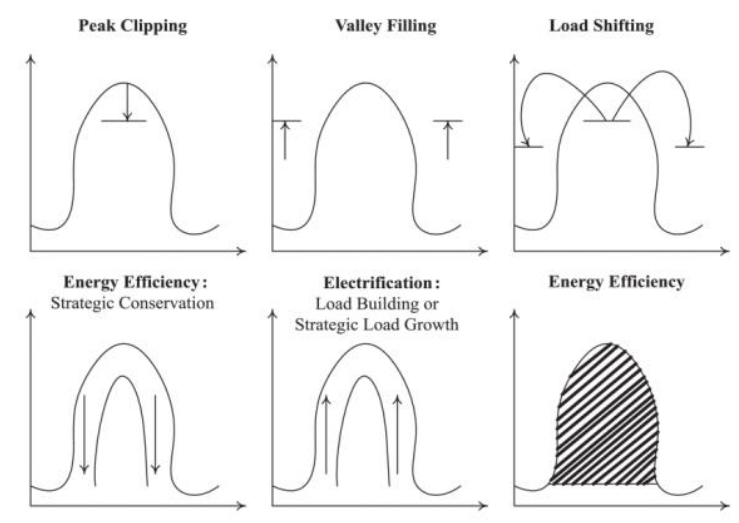

Figure 1. DSM strategies [21]

Fuzzy Logic (FL) based EMS have been developed to reduce cost, energy consumption, and Peak to Average Ratio (PAR) without sacrificing comfort and to improve further decision making regarding intelligent fault detection [22-24]. For example, an FLC has obtained savings of $15 \%$ and $18.5 \%$ in electricity costs, respectively, during peak periods by shifting loads from peak periods with high electricity prices to hours with low electricity prices, resulting in [22]. Intuitive optimization techniques with FL are used for planning controllable devices to reduce PAR in addition to cost and energy consumption [23]. Also, there are studies for the same aim [21, 25]. Based on DSM strategy, Genetic Algorithm (GA) is used to solve the scheduling and optimization problem [25], a constraint-based Multi-Objective Optimization (MOO) method is used in day-ahead scheduling, and a hybrid bacterial foraging algorithm and GA optimization technique are used to control the efficiency of the system. PAR and electricity costs reduced by $50 \%$ and $40 \%$ respectively [21], and by $22.63 \%$ and $22.77 \%$ [25].

A game theory-based strategy that takes DMS into account has also been developed [26, 27]. In another study, first household appliances modeled as controllable and uncontrollable loads then presented a scheduling framework to optimize consumption cost, user comfort, and PAR with an enhanced normalized normal constraint strategy. A significantly lower cost of 104.30 cents per day is achieved [26].

There are studies on combining supply-demand perspectives in one approach based on DSM strategy, on both time and event-based building automation, on EMS for smart homes that allow them to make changes when needed, used in smart meters or measuring devices [19, 28, 29]. An algorithmic simulation is applied to understand the power 
demand in 1 hour per day [28]. Unlike other studies, an electricity meter with a data logger and logic interface is designed on the IzoT platform [29]. While [19] providing cost savings of more than $10 \%$ with their proposed strategy in experimental results, [29] stated that occupancy signals should be correlated with available power data to provide accurate information about the demand level.

\subsection{Demand Side Response}

DR is an electricity market mechanism where consumers can reduce consumption during energy price fluctuations or when the electricity grid reaches critical levels. Programs that allow demand change by responding to a control signal sent from network to users at times of high consumption are called DR [30]. DR-based EMSs developed to examine coordinated control of household appliances, limit the load demand at certain times of a day, schedule household appliances based on dynamic pricing signals, and learn air-conditioning weighted controllable loads [31-35]. Integrated automation of DR, Photovoltaic (PV), and ice storage are examined to achieve demand reduction targets. Experiments in office building have shown that, in addition to DR and ice storage, PV helps further to reduce demand at higher tariffs [31]. A new binary backtracking search algorithm was proposed and compared with Particle Swarm Optimization (PSO) method. The proposed controller provided energy savings of $4.87 \mathrm{~kW}$ on weekdays and $6.6 \mathrm{~kW}$ on weekend days, while energy savings of the PSO controller were $4.52 \mathrm{~kW}$ and $6.3 \mathrm{~kW}$ during DR periods, respectively [32]. An interdisciplinary approach is presented that combines machine learning, optimization, and data structure design to create a DR home EMS. In simulation results for actual weather conditions, learning-based DR and EMS were efficient among other tested DR algorithms [33].

Many studies have also been done on demand uncertainties and scheduling problems. For example, ondemand uncertainty and scheduling problems, Mixed-Integer Non-Linear Programming (MINLP) is used to solve the scheduling problem in their proposed models and [36-39]. The EMS is designed by taking into account TOU pricing together with DR [37]. In the simulation results, [37] a reduction of $29.5 \%-31.5 \%$, [38] achieved reduction in energy costs as $19.5 \%$ and $25.6 \%$ (when demand elasticity exists) according to two different energy management strategies. [36] stated that proposed model not only eliminates demand-side uncertainty and reduces $\mathrm{CO} 2$ emissions.

\subsection{Time of Use (TOU)}

General practices aim to minimize energy costs considering energy systems limitations and retail prices that change over time [40]. TOU is the abbreviation for time-of-use electricity rates. These rates are determined by local utilities and vary according to hours of the day. Electricity unit price is higher during peak demand periods and cheaper during low demand periods. There are studies on smart houses, including RES and battery systems, within the scope of different physical restrictions and TOU tariffs to minimize cost and power consumption from grid [4, 41-43]. An adaptive TOU-Model Predictive Control (MPC) management system is designed in a real-time electricity pricing environment. Energy cost optimization is realized as $49,059 \%$ of the total energy demand in low demand and 46,072\% in high demand [41]. An EMS is developed based on estimations of output of PV integrated to building, uncontrollable loads, and outdoor temperature. The operation of all components is optimized with synergistic distribution of source-load-storage area using MOO within scope of TOU price [4]. Home appliances based on the TOU pricing scheme have been efficiently planned. By using PSO, consumer's bill was reduced by more than $29 \%$, and even in the case of only feeding on grid, the bill is reduced by $19.36 \%$ [42]. A real-time, rule-based control algorithm, taking into account TOU pricing, is proposed to avoid high peak demand. The algorithms following PV, battery, and grid reduced electricity cost significantly [43]. Also, deep neurofuzzy optimization by combining FL and neural networks is proposed to provide energy and cost savings using TOU tariffs [44]. The operation status of devices from total demand data of houses is determined with neuro-fuzzy and non-invasive load monitoring techniques [45].

\subsection{Scheduling and Optımızation}

DSM also uses energy storage units to store energy during offpeak hours and discharge it during peak hours [46]. With the application of RES in modern buildings, the system becomes more complicated due to extraordinary uncertainties in electricity generation besides saving [4]. In this respect, relatively new applications for DSM help grid operators to balance intermittent generation of wind and solar units, especially with timing and sizing of energy demand [46]. In many studies, battery systems and active load control have been investigated to optimize load predictability against uncertainties in RES generation and to solve the scheduling problem [47-58]. A smart meter and smart DSM system using FL-based algorithms by addressing the uncertainties of RES is implemented and achieved $15 \%$ energy savings by providing digital communication [47]. An FL-based smart controller is developed to control charge and discharge status of the battery according to the power generation of PV and consumption status [48]. A new FL-based EMS is proposed to increase the use of RES power supply and reduce energy consumption via offload. In addition, tests are carried out using actual meteorological data from the Adrar region [49].

Studies have also been carried out on FL-based management strategies to operate power system control successfully due to the difficulty of load fluctuation [50-52]. [52] have shown in the study that FL not only provides the load, but diesel generator helps to keep battery charged only in the event of an unforeseen power outage. Intermittent and variable energy generation characteristics of RES negatively affect nominal voltage and frequency values of the system. FL-based intelligent control strategies are proposed to ensure continuity of power supply in case of grid failure for voltage and frequency regulation by [59] and improve the focusing properties of the system response to the uncertainties of RES parameters by [50]. In the simulation results, [50] reduced deviations in frequency, while [59] confirmed that they kept frequency and voltage at optimum limits and ensured their stability.

Among studies on RES generation uncertainty, estimations are modeled and solved as MILP in [54], as MINLP problems in [58]. In [55], while optimizing the cost of customer in the DR program, taking into account uncertainty in RES generation, the electricity bill is reduced up to $42 \%$ with proposed stochastic EMS model [55]. 
The Lyapunov optimization method depends on an online energy management algorithm based on event triggering and instant data to plan controllable loads for solving the energy scheduling problem in a house equipped with PV devices. The electricity bill is less with the proposed algorithm without compromising user's comfort [56]. On the other hand, a column and constraint generation algorithm are adopted to solve with MILP in optimization model for uncertainties and scheduling [57]. Furthermore, MILP technique is used to optimize integration of RES, storage systems, and switchable electric vehicles [60].

A risk-based decision-making framework is created for the SB EMS in case of supply and demand uncertainty in building integrated with wind power. The MILP problem is solved in modeled EMS. Using a proposed microgrid-based system, approximately 92\%, 93\%, and $85 \%$ savings are achieved in total cost, energy supply cost, and total emission costs, respectively, respectively [53].

The integration difficulties caused by stochastic structures of RES and battery systems are studied in [61]. The constrained optimization problem is formulated as a mathematically multiple knapsack problem and then solved using heuristic GA, binary PSO, wind-driven optimization, bacterial foraging optimization, and hybrid GA-PSO algorithms. The integration of RES and energy storage systems resulted in a $19.94 \%$ and $21.55 \%$ reduction in electricity bills and PAR. In addition, home EMS based on a hybrid algorithm outperformed other heuristic algorithms, reducing the bill by $25.12 \%$ and PAR by $24.88 \%$.

Multi-agent systems are used for monitoring and optimal control of homes, buildings, and microgrid systems with controllable loads and RES. [62] stated that it is possible to guarantee safe and optimum system operation, especially through agent-based storage system control. Regarding scheduling, a simple estimation algorithm is presented for uncontrollable loads, using minimal data and calculations. The other motion detection or outdoor temperature sensors aren't used. The 24-hour prediction error of the algorithm is between $8.2 \%$ and $6.2 \%$ in summer months and between $11.4 \%$ and $15.9 \%$ in winter months [63]. In EMS developed in another study, PV panels, small wind turbines, batteries, and the scheduling of controllable loads were optimized with GA for minimum energy cost. With this algorithm, consumed power is reduced at discharge load from $496.5 \mathrm{~kW}$ to 191.5 $\mathrm{kW}$ while providing an average gain of $25.23 \%$ from the annual electricity bill and improving RES utilization by $61.43 \%$ [64].

Unlike other studies concept of SB cluster is proposed for operation of more than one SB in smart grid environment. The designed model has benefited more effectively from advantages of DS and RES, reducing the total electricity cost of SBs by $4.6 \%$ and providing the characteristic optimization of the load [65]. On the other hand, a two-level (local and general EMS) optimization algorithm focused on total electricity cost and thermal comfort level of multiple smart homes with distributed energy sources is proposed. The results showed that proposed distributed algorithm achieved almost the same performance as central electrical optimization algorithm [66].
An optimum switching control model is proposed under practical constraints such as electricity cost, balance of demand, and PV output under TOU program in one of the studies carried out to make adequate use of solar energy. In the results, that monthly electricity bill is decreased to about $50 \%$ [67]. In an EMS, the hybrid system within scope of TOU is modeled to minimize electricity cost while matching user demand and PV output. MPC is used which can learn environmental situations [68]. A model with FLC combined with cost-benefit analysis is created to assess the real economic benefits of load schedule. In cost-benefit analysis, economic comfort is associated with matching generation and consumption patterns for all PV system sizes [69-71]. A multi collector-based online fuzzy coordination algorithm is presented for charging electric vehicles. The results stated that such integration of transportation industry, proper use of clean energy, and reduction of load fluctuation resulted in an $87 \%$ improvement in load factor [72,73]. In [74], home EMS within the framework MILP for a joint evaluation of RES generation system, electric vehicles, and the dual use of the energy storage system and DR strategies [75]. With their proposed strategy achieved cost savings of up to $65 \%$.

\section{MODEL AND CASE STUDY}

In this study, a housing model has been studied to increase energy efficiency in buildings.

In addition, electricity generation with wind and solar RES has been modeled and integrated into the system. Wind turbine and PV generations are modeled based on changes in data obtained from measurement station used for Göztepe, Istanbul, in a thesis study. The control procedure is set to improve current power profile, avoid interruption by managing device according to comfort preferences and prioritize user approval. The Simulink model of the study is shown in Figure 2 and includes five separate sections: the most commonly used devices in residences, power consumed by each device, total power cost, RES, and FLC. Output signals of devices are power consumptions and collected as input of FLC. The other inputs of FLC are time, output of clock, and generated power by RES that is output of RES model.

Typically, devices can be divided into two categories, controllable and uncontrollable devices. Controllable devices can be closed or partially used by controllers. Uncontrollable devices are passive loads that cannot be switched off or made partially. Table I shows the category and power consumption of each load.

TABLE I

LOAD CATEGORIES AND POWER CONSUMPTIONS Controllable loads Uncontrollable loads

\begin{tabular}{cccc}
\hline & & & \\
HVAC & $2500 \mathrm{~W}$ (winter), & Washing & \\
1944(summer) & machine & $303 \mathrm{~W}$ \\
Water heater & $1500 \mathrm{~W}$ & Dish washer & $510 \mathrm{~W}$ \\
Lamp & $15 \mathrm{~W}$ & Oven & $2000 \mathrm{~W}$ \\
Refrigerator & $120 \mathrm{~W}$ & Iron & $350 \mathrm{~W}$ \\
TV, PC & $100 \mathrm{~W}$ & & \\
\hline
\end{tabular}




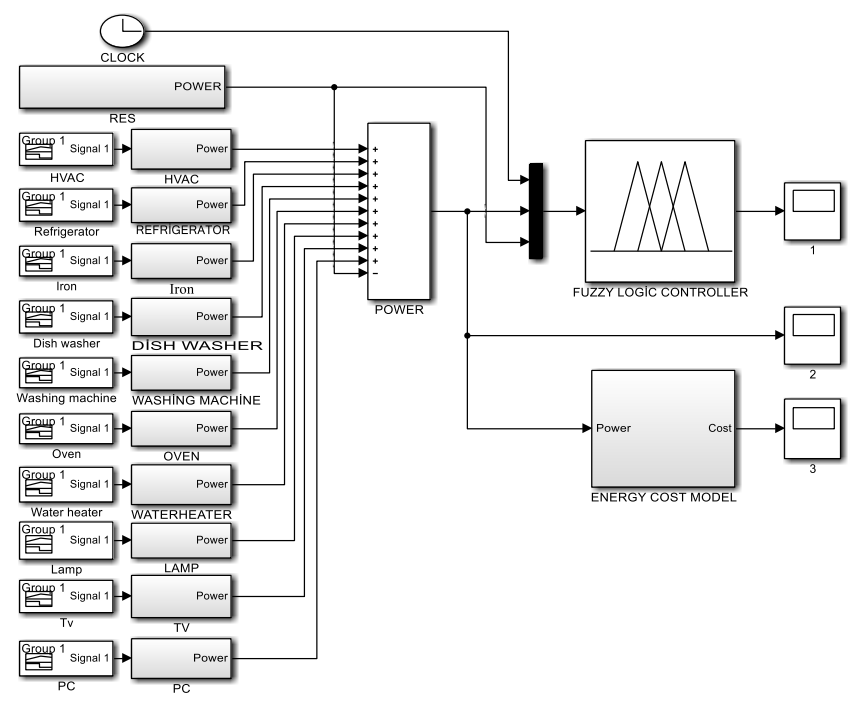

Figure 2. Simulink model of residential devices and control system [2].

\subsection{Fuzzy Logic Controller}

FLC is designed for scheduling power consumption. FL provides control overloads in line with priority given. Based on 3-time tariff in Turkey, FL based controller defines nonpriority loads to be turned off when consumers increase their consumption during hours when there is no RES generation, and the unit price of electricity is high. In this case, the controller ensures that power supplied to high priority loads is used appropriately by suggesting that some loads are cut, encouraging them to be shifted to off-peak and RES generation hours. The controller also keeps energy consumption within a certain limit, which means that it cannot exceed limit during high consumption hours; consumer approval takes precedence.

Figure 3 shows block diagram of FLC with 75 rules, three input signals, and two output signals. The input and output signals of FLC are as follows.

"Electricity Price": Sampled over 24 hours. It defines hours when the unit price of electricity is low or expensive.

"Power Demand": It is the load consumption demand according to the operating times of the existing devices.

"Renewable Energy": It is 24-hour generation of PV and wind turbine.

"Load Scheduling": It is amount of load to be shifted in kW.

"Run Loads": The total load in kW that controller will allow to operate in a given time.

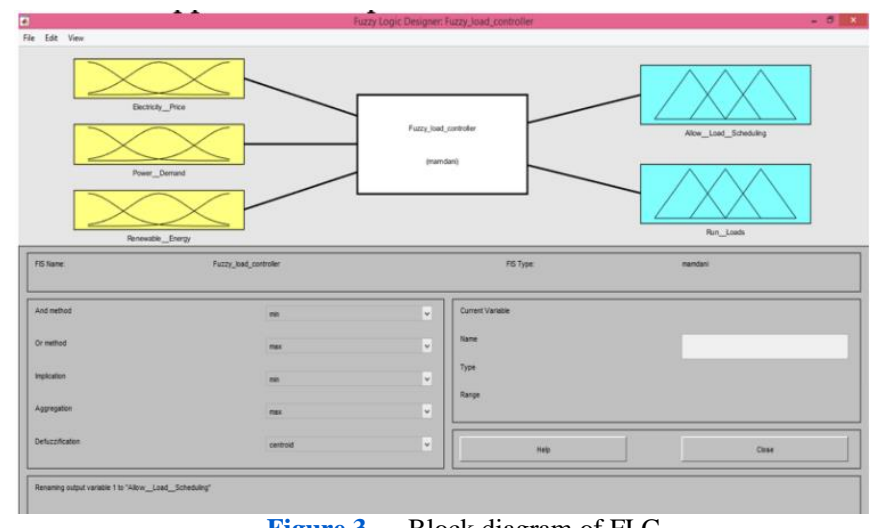

Figure 3. Block diagram of FLC.

\subsection{Fuzzy Membership Functions}

Among membership functions, input and output signals of FLC membership functions were selected by trial\&error method. According to 3-time tariff, membership functions of "Electricity Price" input were set as "Night" when the unit price of electricity is low (22:00-06:00), "Day" when it is medium (06:00-17:00), and "Peak" when it is expensive (17:00-22:00). All input and output membership functions are shown in Figures 4, 5, 6, 7, 8 .

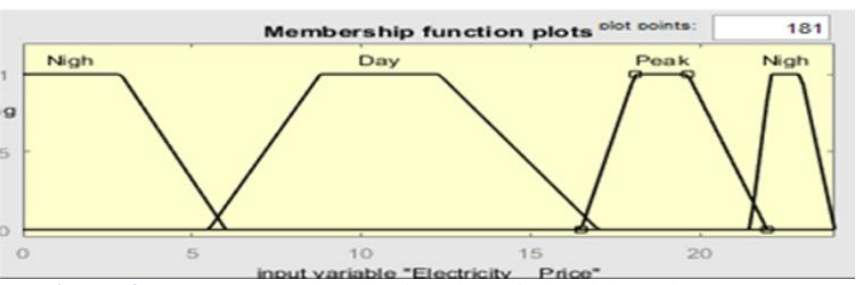

Figure 4. Fuzzy membership function of electricity price (Input 1).

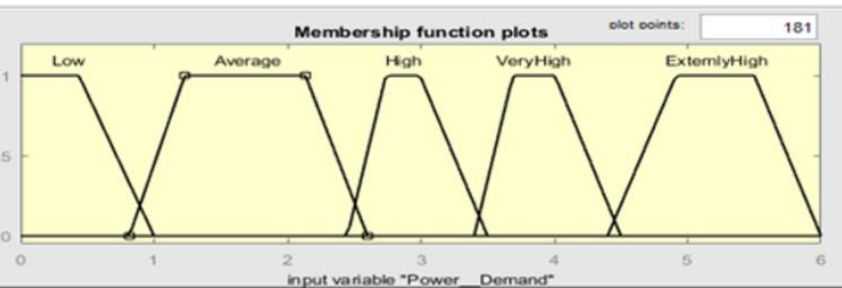

Figure 5. Fuzzy membership function of power demand (Input 2).

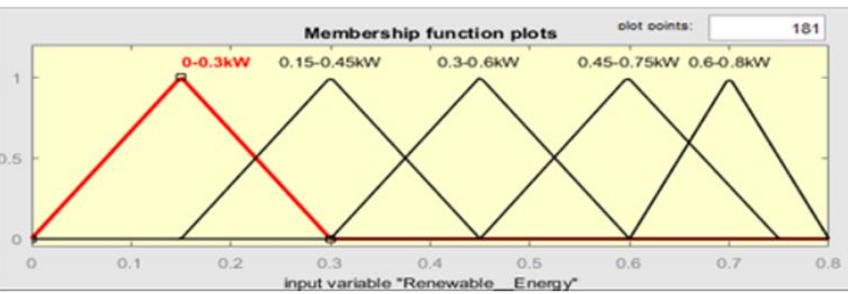

Figure 6. Fuzzy membership function of renewable energy (Input 3).

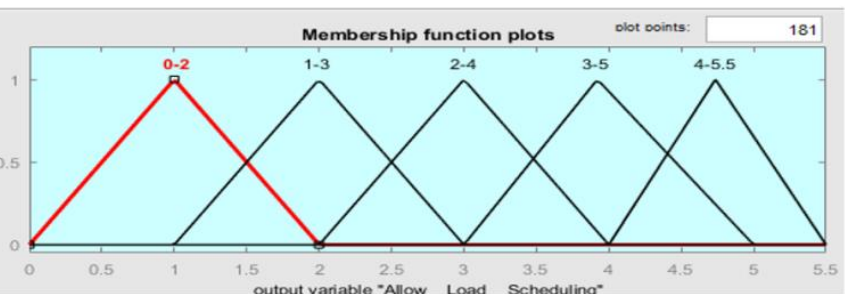

Figure 7. Fuzzy membership function of load scheduling (Output 1).

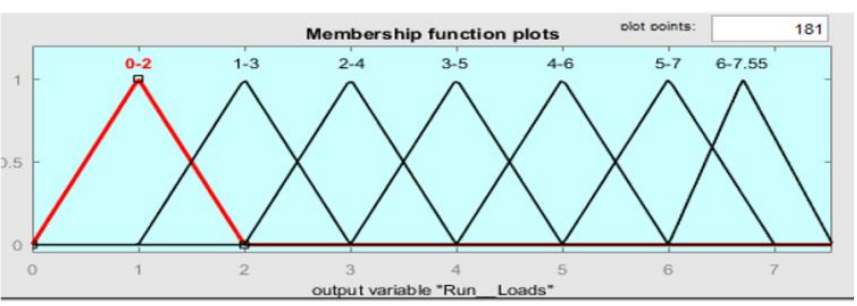

Figure 8. Fuzzy membership function of run loads (Output 2).

Depending on the number of membership functions considered in input and output blocks, 75 rules were created, considering the needs and constraints.

\subsection{Case Study}

In this study, energy management and efficiency in smart buildings were examined in four cases.

1. Energy consumption in uncontrolled SB,

2. Energy consumption in SB with FLC, 
3. Energy consumption in uncontrolled SB with RES,

4. Energy consumption in SB with FLC and RES.

For all four cases, analyses made by considering summer and winter days and simulation results were compared.

First, the energy consumption and cost of uncontrolled building and building with FLC are compared and are shown in Figure 9 and Figure 10 for the winter and summer days, respectively

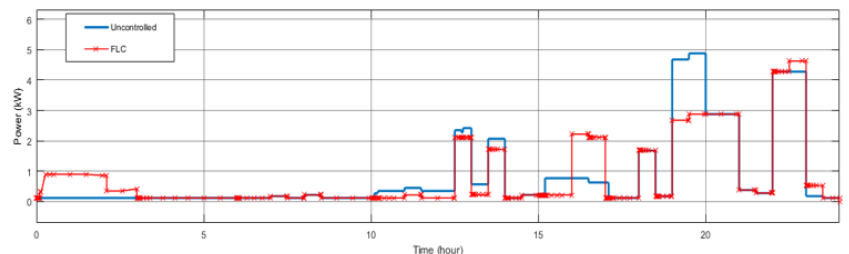

(a)

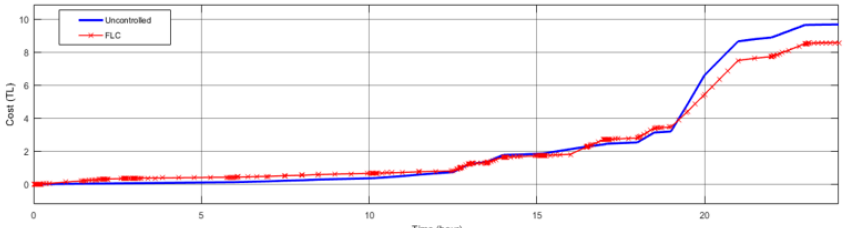

(b)

Figure 9. Comparison of power consumption (a) and cost (b) of uncontrolled building and building with FLC for a winter day.

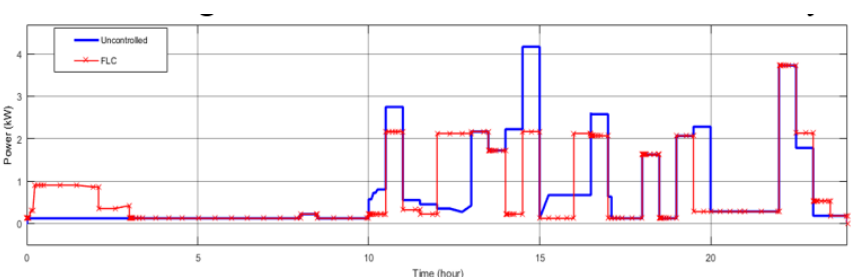

(a)

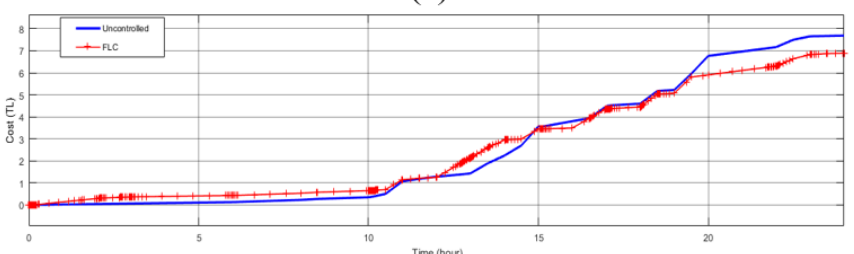

(b)

Figure 10. Comparison of power consumption (a) and cost (b) of uncontrolled building and building with FLC for a summer day.

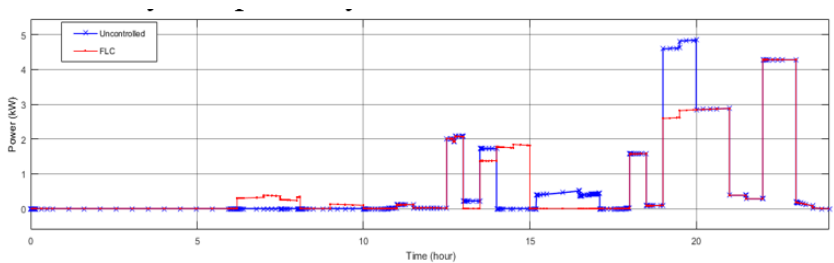

(a)

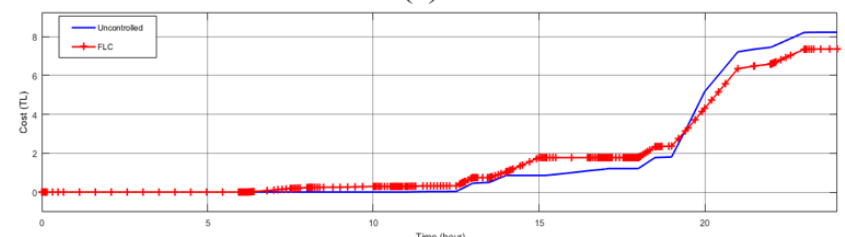

(b)

Figure 11. Comparison of power consumption (a) and cost (b) of uncontrolled buildings with RES and with RES and FLC for a winter day.

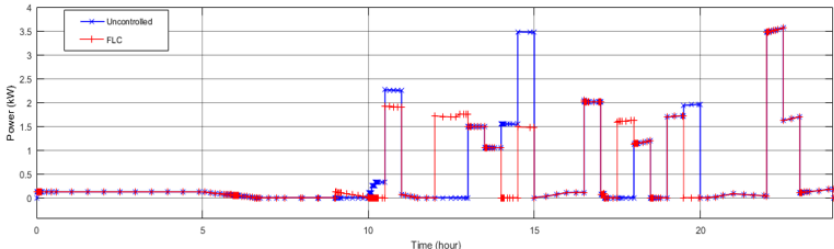

(a)

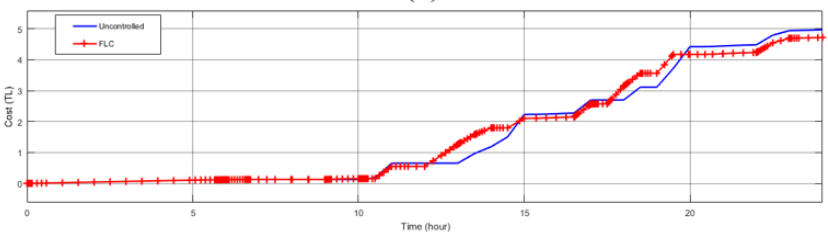

(b)

Figure 12. Comparison of power consumption (a) and cost (b) of uncontrolled buildings with RES and with RES and FLC for a summer day.

There was no change in total energy consumption for both seasons since operation of loads was shifted only in time. In addition, a daily provide saved of $1.10 \mathrm{TL}(11.36 \%)$ in winter and $0.80 \mathrm{TL}(10.41 \%)$ in summer in cost of building with FLC compared to cost of a building uncontrolled.

The energy consumption of uncontrolled buildings with RES and with RES and FLC are shown in Figure 11 and Figure 12 for winter and summer days, respectively.

The building with FLC and RES has been saved $0.62 \mathrm{~kW}$ $(3.88 \%)$ and $0.86 \mathrm{TL}(10.46 \%)$ in winter, $0.49 \mathrm{~kW}(4.05 \%)$, and $0.25 \mathrm{TL}(5.03 \%)$ in summer, compared to an uncontrolled building with RES.

The highest total energy consumption and cost were obtained as $19.74 \mathrm{~kW}, 9.69 \mathrm{TL}$ in winter, $17.88 \mathrm{~kW}$, and 7.69 TL in summer, in the case that without a controller and so control is dependent on user. The lowest consumption price was $7.36 \mathrm{TL}$ in winter, $4.72 \mathrm{TL}$ in summer, and minimum energy consumption of $15.35 \mathrm{~kW}$ in winter and $11.62 \mathrm{~kW}$ in summer, for building with FLC and RES.

\section{CONCLUSION}

This study examines innovative energy management approaches based on modeling and optimization techniques, which have recently attracted attention due to increasing awareness of energy efficiency. While there is much experience in optimizing energy generation, distribution, and consumption, the demand-side has received increasing attention from academia and industry as a function of EMS.

In this study, a case study was carried out by considering need to increase energy efficiency on a residential model and taking into account comfort, cost, RES, and DR within the scope of DSM. Energy consumption and energy cost results are investigated of four SB conditions for summer and winter days. The four SB conditions are uncontrolled SB, FLC controlled SB, uncontrolled SB with RES, FLC controlled SB with RES. The building with FLC and RES has been saved $3.88 \%$ energy and $10.46 \%$ cost in winter, $4.05 \%$ energy, and $5.03 \%$ cost in summer, compared to an uncontrolled building with RES.

The best result in the case study is obtained by feeding system from RES if there is generation, limiting power consumption of some loads during peak hours if there is no renewable energy generation and shifting these loads to the RES 
generation time or off-peak period. So, SB with FLC and RES makes the best use of RES and consumes the least energy from grid compared to other situations.

\section{ACKNOWLEDGEMENT}

The authors thank to Bilgin for contributing to this research by providing data collected for M. Bilgin, "Fotovoltaik Panellerin Verimine Panel Yüzey Sicakliği Etkisinin İncelenmesi," Master Thesis, Marmara University, Istanbul, Turkey, 2013.

\section{REFERENCES}

[1] L. Hurtado, P. Nguyen, W. Kling, W. Zeiler, "Building energy management systems-Optimization of comfort and energy use," presented at the 48th International Universities' Power Engineering Conference, Dublin, Ireland, Sept. 2-5, 2013.

[2] M. P. Fanti, A. M. Mangini, M. Roccotelli, "A simulation and control model for building energy management," Control Engineering Practice, vol. 72, pp. 192-205, 2018.

[3] P. H. Shaikh, N. B. M. Nor, P. Nallagownden, I. Elamvazuthi, "Intelligent multi-objective optimization for building energy and comfort management," Journal of King Saud University-Engineering Sciences, vol. 30, no. 2, pp. 195-204, 2018.

[4] F. Wang, L. Zhou, H. Ren, X. Liu, S. Talari, M. Shafie-khah, J. P. Catalao, "Multi-objective optimization model of source-load-storage synergetic dispatch for a building energy management system based on TOU price demand response," IEEE Transactions on Industry Applications, vol. 54, no. 2, pp. 1017-1028, 2017.

[5] O. Akar, U. K.Terzi, T. Sonmezocak and B.K. Tuncalp. "Determination of the optimum Hybrid renewable power system: a case study of Istanbul Gedik University Gedik Vocational School", Balkan journal of electrical\&computer engineering, Vol.7, No.4, pp.456-463, 2019.

[6] U. Civan, "Akıllı binaların çevresel sürdürülebilirlik açısından değerlendirilmesi," Master Thesis, İstanbul Teknik University, Istanbul, Turkey, 2006.

[7] F. M. Bhutta, "Application of smart energy technologies in building sector-future prospects," IEEE International Conference on Energy Conservation and Efficiency, Pakistan, Lahore, Nov. 22-23 2017.

[8] A. Altayeva, B. Omarov, Y. Im Cho, "Multi-objective optimization for smart building energy and comfort management as a case study of smart city platform," presented at the 19th International Conference on High Performance Computing and Communications; IEEE 15th International Conference on Smart City; IEEE 3rd International Conference on Data Science and Systems, Bangkok, Thailand, Dec.18$20,2017$.

[9] S. Smitha, J. Savier, F. M. Chacko, "Intelligent control system for efficient energy management in commercial buildings," Annual International Conference on Emerging Research Areas and International Conference on Microelectronics, Communications and Renewable Energy, Kanjirapally, India , June 4-6, 2013.

[10] D. Mariano-Hernández, L. Hernández-Callejo, A. Zorita-Lamadrid, O. Duque-Pérez, F. S. García, "A review of strategies for building energy management system: model predictive control, demand side management, optimization, and fault detect \& diagnosis," Journal of Building Engineering, p. 101692, 2020.

[11] I. T. Erhan, "Akıllı binalarda aydınlatma otomasyonunun enerji verimliliğine katkısının incelenmesi," Master Thesis, Istanbul University, Istanbul, Turkey, 2018.

[12] H. Kılıç, "Akıllı binalar, kurulmaları ve işletilmeleri," Master Thesis, İstanbul Teknik University, Istanbul, Turkey, 2007.

[13] H. M. Günaydın, and S. Zağpus. "Türkiye'de Bina Otomasyon Sistemlerinin Mimarlar Tarafindan Algılanması, Akıllı Bina Tasarım Süreci ve Kalitesi”. VI. Ulusal Tesisat Mühendisliği Kongresi ve Sergisi. https://www1.mmo.org.tr/resimler/dosya_ekler/28aa8ac200e659d_ek. $\mathrm{pdf}$

[14] Ö. Karadişoğulları, "Akıllı binalarda kullanılan sistemlerin sürdürülebilirlik bağlamında irdelenmesi," Master Thesis, Haliç University, Istanbul,Turkey, 2013.

[15] Bilgi Teknolojileri ve İletişim Kurumu, "Elektronik Haberleşme Sektöründe Teknolojik Gelişmeler ve Eğilimler Raporu," Ankara, 2014.

[16] J. Smiciklas, F. Spitzer, .A. Hay, R. Delgado, S. Kondepudi "Intelligent sustainable buildings for smart sustainable cities"," ITU-T Focus Group on Smart Sustainable Cities, Focus Group Technical Report, 2015.

[17] D. Minoli, K. Sohraby, B. Occhiogrosso, "IoT considerations, requirements, and architectures for smart buildings-Energy optimization and next-generation building management systems," IEEE Internet of Things Journal, vol. 4, no. 1, pp. 269-283, 2017.

[18] P. Palensky, D. Dietrich, "Demand side management: Demand response, intelligent energy systems, and smart loads," IEEE transactions on industrial informatics, vol. 7, no. 3, pp. 381-388, 2011.

[19] M. Batić, N. Tomašević, G. Beccuti, T. Demiray, S. Vraneš, "Combined energy hub optimisation and demand side management for buildings," Energy and Buildings, vol. 127, pp. 229-241, 2016.

[20] M. Zehir, M. Bağrıyanık, "Akıllı Şebekelerde Gelişmiş Yerel Talep Yönetimi," V. Enerji verimliliği ve Kalitesi Sempozyumu, Istanbul, Turkey, pp. 14-18, 2013.

[21] A. Khalid, N. Javaid, M. Guizani, M. Alhussein, K. Aurangzeb, and M. Ilahi, "Towards dynamic coordination among home appliances using multi-objective energy optimization for demand side management in smart buildings," IEEE access, vol. 6, pp. 19509. $19529,2018$.

[22] F. Alfaverh, M. Denai, Y. Sun. "Demand response strategy based on reinforcement learning and fuzzy reasoning for home energy management," IEEE Access, vol. 8, pp. 39310-39321, 2020.

[23] R. Khalid, N. Javaid, M. H. Rahim, S. Aslam, A. Sher. "Fuzzy energy management controller and scheduler for smart homes," Sustainable Computing: Informatics and Systems, vol. 21, pp. 103-118, 2019.

[24] V. Mpelogianni, K. Giannousakis, E. Kontouras, P. P. Groumpos, D. Tsipianitis. "Proactive Building Energy Management Methods Based On Fuzzy Logic And Expert Intelligence," IFAC-PapersOnLine, vol. 52, no. 25, pp. 519-522, 2019.

[25] M. B. Rasheed, N. Javaid, M. Awais, Z. A. Khan, U. Qasim, N. Alrajeh, Q. Javaid. "Real time information based energy management using customer preferences and dynamic pricing in smart homes," Energies, vol. 9, no. 7, p. 542, 2016.

[26] M. Waseem, Z. Lin, S. Liu, Z. Zhang, T. Aziz, D. Khan, "Fuzzy compromised solution-based novel home appliances scheduling and demand response with optimal dispatch of distributed energy resources," Applied Energy, vol. 290, p. 116761, 2021.

[27] M. I. Ghiasi, A. Hajizadeh, M. A. Golkar, M. Marefati, "Demand and supply side management strategies for zero energy buildings," IEEE 17th International Conference on Ubiquitous Wireless Broadband (ICUWB), Salamanca, Spain, Sept. 2-15, 2017.

[28] W. Li, T. Logenthiran, W. L. Woo, V.-T. Phan, D. Srinivasan. "Implementation of demand side management of a smart home using multi-agent system," IEEE Congress on Evolutionary Computation (CEC), Vancouver, BC, Canada, July 24-29, 2016.

[29] A. Ożadowicz and J. Grela. "An event-driven building energy management system enabling active demand side management," Second International Conference on Event-based Control, Communication, and Signal Processing, Krakow, Poland, June 13-15, 2016.

[30] M. M. Rahman, S. Hettiwatte, S. Gyamfi, "An intelligent approach of achieving demand response by fuzzy logic based domestic load management," Australasian Universities Power Engineering Conference, Perth, WA, Australia, Sept. 28, 2014.

[31] F. Sehar, M. Pipattanasomporn, S. Rahman, "An energy management model to study energy and peak power savings from PV and storage in 
demand responsive buildings," Applied Energy, vol. 173, pp. 406-417, 2016.

[32] M. S. Ahmed, A. Mohamed, T. Khatib, H. Shareef, R. Z. Homod, J. Abd Ali, "Real time optimal schedule controller for home energy management system using new binary backtracking search algorithm," Energy and Buildings, vol. 138, pp. 215-227, 2017.

[33] D. Zhang, S. Li, M. Sun, Z. O’Neill, "An optimal and learning-based demand response and home energy management system," IEEE Transactions on Smart Grid, vol. 7, no. 4, pp. 1790-1801, 2016.

[34] Z. Nadeem, N. Javaid, A. W. Malik, S. Iqbal, "Scheduling appliances with GA, TLBO, FA, OSR and their hybrids using chance constrained optimization for smart homes," Energies, vol. 11, no. 4, p. 888, 2018.

[35] V. Pradhan, V. M. Balijepalli, S. A. Khaparde, "An effective model for demand response management systems of residential electricity consumers," IEEE Systems Journal, vol. 10, no. 2, pp. 434-445, 2014.

[36] A. Baldauf, "A smart home demand-side management system considering solar photovoltaic generation," present at the 5th International Youth Conference on Energy, Pisa ,Italy, May 27-30, 2015.

[37] M. A. F. Ghazvini, J. Soares, O. Abrishambaf, R. Castro, Z. Vale, "Demand response implementation in smart households," Energy and Buildings, vol. 143, pp. 129-148, 2017.

[38] J. K. Gruber, M. Prodanovic, "Two-stage optimization for building energy management," Energy Procedia, vol. 62, pp. 346-354, 2014.

[39] Z. Xu, Q.-S. Jia, X. Guan, "Supply demand coordination for building energy saving: Explore the soft comfort," IEEE Transactions on Automation Science and Engineering, vol. 12, (2), pp. 656-665, 2014.

[40] J. K. Gruber, F. Huerta, P. Matatagui, M. Prodanović, "Advanced building energy management based on a two-stage receding horizon optimization," Applied Energy, vol. 160, pp. 194-205, 2015.

[41] M. Yilmaz, "Real measure of a transmission line data with load forecast model for the future", Balkan Journal of Electrical and Computer Engineering 6 (2), 141-145.

[42] I. Ullah, N. Javaid, Z. A. Khan, U. Qasim, Z. A. Khan, S. A. Mehmood, "An incentive-based optimal energy consumption scheduling algorithm for residential users," Procedia Computer Science, vol. 52, pp. 851-857, 2015.

[43] H. A. Özkan, "A new real time home power management system," Energy and Buildings, vol. 97, pp. 56-64, 2015.

[44] S. Javaid, M. Abdullah, N. Javaid, T. Sultana, J. Ahmed, N. A. Sattar, "Towards Buildings Energy Management: Using Seasonal Schedules Under Time of Use Pricing Tariff via Deep Neuro-Fuzzy Optimizer," presented at the15th International Wireless Communications \& Mobile Computing Conference, Tangier, Morocco, June 24-28, 2019.

[45] M. Z. Abbas, I. A. Sajjad, R. Liaqat, M. Abdullah, M. A. Shah, M. F. Nadeem, "Non-intrusive Load Monitoring for Residential Customers Using Adaptive-Neuro Fuzzy Interface System and Fine Tree Classifier," presented at the 23rd International Multitopic Conference, Bahawalpur, Pakistan, Nov. 5-7, 2020.

[46] A. Pina, C. Silva, P. Ferrão, "The impact of demand side management strategies in the penetration of renewable electricity," Energy, vol. 41, no. 1, pp. 128-137, 2012.

[47] D. Karna, A. Vikram, A. Kumar, M. Rizwan, "A Novel Fuzzy based Intelligent Demand Side Management for Automated Load Scheduling," presented at the 4th International Conference on Green Energy and Applications, Singapore, March 7-9, 2020.

[48] K. P. Sharma, N. Baine, "Application of a Fuzzy Logic based Controller for Peak Load Shaving in a Typical Household," IEEE International Conference on Fuzzy Systems (FUZZ-IEEE), New Orleans, LA, USA, June 23-26, 2019.

[49] A. Saidi, A. Harrouz, I. Colak, K. Kayisli, R. Bayindir, "Performance Enhancement of Hybrid Solar PV-Wind System Based on Fuzzy Power Management Strategy: A Case Study," 7th International Conference on Smart Grid, Newcastle, NSW, Australia, Dec. 9-11, 2019.
[50] M. Elsisi, N. Bazmohammadi, J. M. Guerrero, M. A. Ebrahim, "Energy management of controllable loads in multi-area power systems with wind power penetration based on new supervisor fuzzy nonlinear sliding mode control," Energy, vol. 221, p. 119867, 2021.

[51] W. Dong, Q. Yang, X. Fang, W. Ruan, "Adaptive optimal fuzzy logic based energy management in multi-energy microgrid considering operational uncertainties," Applied Soft Computing, vol. 98, p. 106882, 2021.

[52] K. Meje, L. Bokopane, K. Kusakana, M. Siti, "Optimal power dispatch in a multisource system using fuzzy logic control," Energy Reports, vol. 6, pp. 1443-1449, 2020.

[53] H. Golpîra, S. A. R. Khan, "A multi-objective risk-based robust optimization approach to energy management in smart residential buildings under combined demand and supply uncertainty," Energy, vol. 170, pp. 1113-1129, 2019.

[54] R. Hemmati, H. Saboori, "Stochastic optimal battery storage sizing and scheduling in home energy management systems equipped with solar photovoltaic panels," Energy and Buildings, vol. 152, pp. 290-300, 2017.

[55] M. Shafie-Khah, P. Siano, "A stochastic home energy management system considering satisfaction cost and response fatigue," IEEE Transactions on Industrial Informatics, vol. 14, no. 2, pp. 629-638, 2017.

[56] W. Fan, N. Liu, J. Zhang, "An event-triggered online energy management algorithm of smart home: Lyapunov optimization approach," Energies, vol. 9, no. 5, p. 381, 2016.

[57] C. Wang, B. Jiao, L. Guo, Z. Tian, J. Niu, S. Li, "Robust scheduling of building energy system under uncertainty," Applied Energy, vol. 167, pp. 366-376, 2016.

[58] D. Setlhaolo X. Xia, "Combined residential demand side management strategies with coordination and economic analysis," International Journal of Electrical Power \& Energy Systems, vol. 79, pp. 150-160, 2016.

[59] Y. Krim, D. Abbes, S. Krim, and M. F. Mimouni, "Intelligent droop control and power management of active generator for ancillary services under grid instability using fuzzy logic technology," Control Engineering Practice, vol. 81, pp. 215-230, 2018.

[60] F. Y. Melhem, O. Grunder, Z. Hammoudan, and N. Moubayed, "Optimization and energy management in smart home considering photovoltaic, wind, and battery storage system with integration of electric vehicles," Canadian Journal of Electrical and Computer Engineering, vol. 40, no. 2, pp. 128-138, 2017.

[61] A. Ahmad et al., "An optimized home energy management system with integrated renewable energy and storage resources," Energies, vol. 10, (4), p. 549, 2017.

[62] A. Anvari-Moghaddam, A. Rahimi-Kian, M. S. Mirian, J. M. Guerrero, "A multi-agent based energy management solution for integrated buildings and microgrid system," Applied Energy, vol. 203, pp. 41-56, 2017.

[63] W. El-Baz, P. Tzscheutschler, "Short-term smart learning electrical load prediction algorithm for home energy management systems," Applied Energy, vol. 147, pp. 10-19, 2015.

[64] S. Arun, M. Selvan, "Intelligent residential energy management system for dynamic demand response in smart buildings," IEEE Systems Journal, vol. 12, (2), pp. 1329-1340, 2017.

[65] L. Ma et al., "Multi-party energy management for smart building cluster with PV systems using automatic demand response," Energy and Buildings, vol. 121, pp. 11-21, 2016.

[66] I.-Y. Joo D.-H. Choi, "Distributed optimization framework for energy management of multiple smart homes with distributed energy resources," IEEE Access, vol. 5, pp. 15551-15560, 2017.

[67] Z. Wu, X. Xia, "Optimal switching renewable energy system for demand side management," Solar Energy, vol. 114, pp. 278-288, 2015.

[68] Z. Wu, H. Tazvinga, X. Xia, "Demand side management of photovoltaic-battery hybrid system," Applied Energy, vol. 148, pp. 294-304, 2015. 
[69] L. Ciabattoni, F. Ferracuti, M. Grisostomi, G. Ippoliti, S. Longhi, "Fuzzy logic based economical analysis of photovoltaic energy management," Neurocomputing, vol. 170, pp. 296-305, 2015.

[70] E. Aykut, UK. Terzi. Techno-economic and environmental analysis of grid connected hybrid wind/photovoltaic/biomass system for Marmara University Goztepe campus. International Journal of Green Energy. 2020 Dec 7;17(15):1036-43.

[71] M Yilmaz, H Kilic "Smart grid road map and challenges for Turkey",IET Digital Library, Microgrids for Rural Areas: Research and case studies, 2020, pp. 389-420.

[72] Ghorai, D. Majumdar, T. Jash, S. Ray, "PV assisted Fuzzy based EV charge scheduling for demand side energy management: a case study," IEEE Calcutta Conference (CALCON), Kolkata, India, Febr. 28-29, 2020.

[73] MS Can, M Sam "Imitation of Fuzzy Logic Controller Based Artificial Neural Network, And Application Of Inverted Pendulum System Control" European Journal of Technique, Volume 9, Issue 2, 121 - 136, 30.12.2019

[74] O. Erdinc, N. G. Paterakis, T. D. Mendes, A. G. Bakirtzis, J. P. Catalão, "Smart household operation considering bi-directional EV and ESS utilization by real-time pricing-based DR," IEEE Transactions on Smart Grid, vol. 6 (3), pp. 1281-1291, 2014.

[75] UK. Terzi , HE Ilhan, H Kaymaz, H Erdal, H. Calik. A Review of Commercial Electric Vehicle Charging Methods. PrometTraffic\&Transportation. 2020 Mar 15;32(2):291-307.

\section{BIOGRAPHIES}

Nazli Hasanova received the B.S. degree in Electrical Engineering from Azerbaijan State Agricultural University in 2017. In 2017, she started her education in the Electrical Electronics Engineering Master's program at Marmara University, Institute of Science and Technology.

Secil Varbak Nese received the B.S. degree in Electrical Education from Kocaeli University, Kocaeli, Turkey, in 2004, the M.S. degree in Electrical Education from the Afyon Kocatepe University, Afyonkarahisar, Turkey, in 2008, and the Ph.D. degree in Electrical Education from the Marmara University, Istanbul, Turkey, in 2015. She is currently an Assistant Professor Dr. at Electrical-Electronics Engineering in Marmara University, Istanbul, Turkey. Her current research interests include power systems, renewable energy. 